\title{
Application of NSO compounds in the research of hydrocarbon migration direction in the Wangjiagang area of the Dongying sag in the Bohai Bay Basin
}

\author{
Zicheng Niu ${ }^{1,2 *}$, Zheng $\mathrm{Li}^{1}$, Xiuhong Wang ${ }^{1}$, Huiping Liu ${ }^{1}$, Juan Wang ${ }^{1}$, Xuan Liu ${ }^{1}$ and Ru Wang ${ }^{1}$ \\ ${ }^{1}$ Research Institute of Petroleum Exploration and Development of Shengli Oil Field Branch Company, SINOPEC, Dongying, China \\ ${ }^{2}$ Working Stations for Postdoctors of Shengli Oilfield Branch Company, SINOPEC, Dongying, China
}

\begin{abstract}
The determination of hydrocarbon migration direction is an important part in the study of petroleum accumulation in petroliferous basins, and plays an important role in guiding oil and gas exploration activity. Despite their relatively low content in petroleum, the polar nitrogen-, sulphur- and oxygencontaining compounds (collectively referred to as NSO compounds) have great potential in characterizing the hydrocarbon migration process. A series of crude oils along hydrocarbon migration pathway were selected and analysed using GC $\times$ GC/TOFMS and GC-MS in the Wangiiagang area of the Dongying sag. Total concentration of NSO compounds and other related parameters are determined to verify the role of different parameters in indicating hydrocarbon migration. Our research result shows that the total amount of NSO compounds, 1-/3-MC ratio, 1,8- /2,7-DMC ratio, 4-/1-MDBF ratio and 2,4-/1,4-DMDBT ratio changes grandully with the increase of migration distances. Thus, these parameters can be applied as effective migration direction indicators in study area. Some other parameters may not be suitable for the identification of hydrocarbon migration direction in the study area.
\end{abstract}

\section{Introduction}

In addition to saturated hydrocarbons and aromatic compounds, crude oil contains relatively low content of polar heteroatomic compounds such as NSO compounds. Although the content of these compounds is relatively low, they have important applications in the study of hydrocarbon source, hydrocarbon migration and hydrocarbon secondary alterations [1]. Hydrocarbon migration occurs throughout the process of reservoir formation, and is an area that needs to be focused on in petroleum exploration activities. The determination of the direction of hydrocarbon migration plays an important role in understanding the process and mechanism of reservoir formation, as well as the discovery of new oil and gas reservoirs. Many scholars have carried out extensive studies with different methods, and determined that the migration direction of hydrocarbons can be analyzed based on the characteristics of maturity, biomarker compounds, isotopes, and fluid inclusions ${ }^{[2-3]}$. With the development of the precision of geochemical analysis methods, more and more scholars have discovered in recent years that polar heteroatom compounds in crude oil can be better used to trace the migration directions ${ }^{[4]}$. Due to the characteristics of the structure of neutral nitrogencontaining compounds and their interaction with rocks or solid organic matter in the reservoir, the absolute concentration of these compounds and the ratio of different isomers will change regularly during petroleum migration. Sulfur-containing compounds and oxygencontaining compounds which have similar structure and interaction mechanism with reservoirs can play the same role in indicating the hydrocarbon migration direction (Figure 1). In this paper, we selected crude oil samples from the Wangjiagang area of Dongying sag, conducted experimental analysis of NSO compounds, and systematically analyzed the variation of relative content of NSO compounds and the typical compound parameters in the migration direction, in order to explore their application in the identification of hydrocarbon migration direction. 

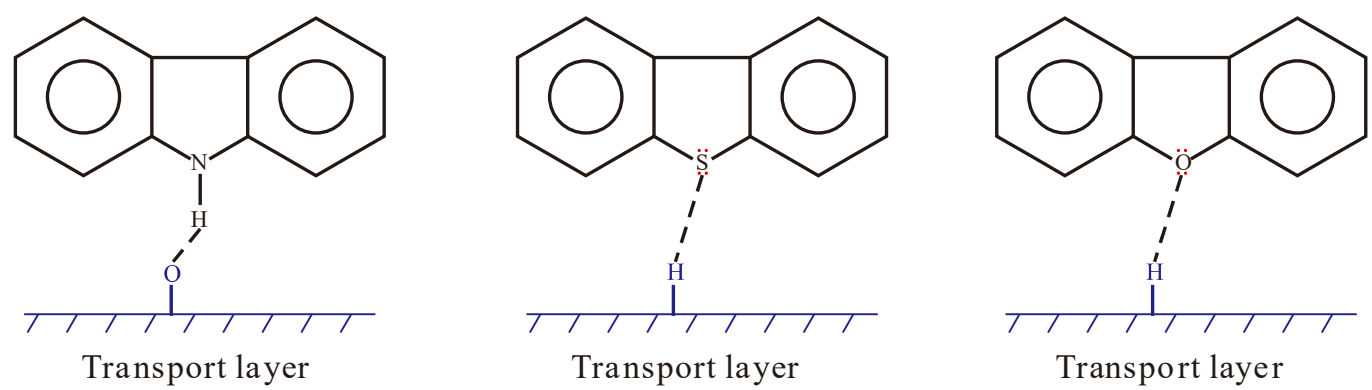

Figure 1. Structures of polar nitrogen-, sulphur- and oxygen- containing compounds and their interaction mechanism with hydrocarbon transport laysers.

\section{Geological background}

The Wangjiagang area is located in the eastern part of the southern slope of the Dongying Sag, adjacent to the Niuzhuang sub-sag in the north, adjacent to the Le'an Oilfield in the south, and the Bamianhe Oilfield and Chunhua Oilfield on the east and west sides, with an exploration area of about $265 \mathrm{~km}^{2}$ (Figure 2). The
Ordovician, Neogene Kongdian Formation (Ek) and Shahejie Formation (Es) are the main hydrocarbonbearing strata. The upper Es 3 , the lower Es 4 and $E_{1}$ are the main source rocks in the study area. The complex tectonic movement formed a series of small NEE-trending faults and and constituted a series of complex small fault blocks in the study area. The oil and gas generated in Niuzhuang sag migrated to Wangjiagang area in a steplike manner through these parallel faults ${ }^{[5]}$.

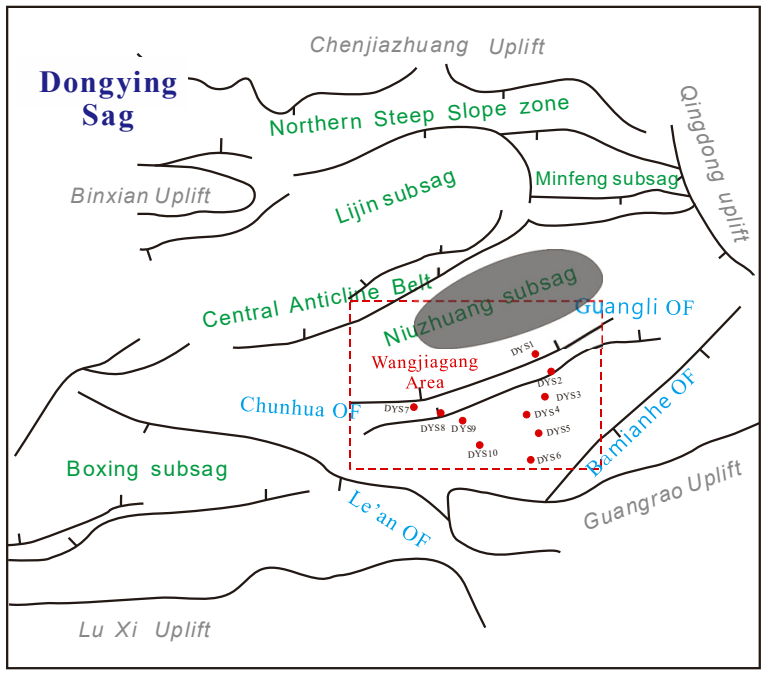

Figure 2. Location map of the study area in the Dongying sag, Bohai Bai Basin. OF: oil field.

\section{Samples and methods}

The crude oil samples used in this study were collected from the wells of Wangjiagang area in the Dongying sag (Figure 2). The crude oil was analysed on $\mathrm{GC} \times \mathrm{GC}$ instrument, having a time-of-flight mass spectrometer (TOFMS) coupled in a series with a gas chromatograph. This method can realize the quantitative analysis of different molecular structure compounds in crude oil, and the relative concentration of $\mathrm{N}-, \mathrm{S}-$, and $\mathrm{O}$ - containing compounds were determined. The nitrogen fractions were isolated from crude oils samples using the method reported by previous scholars ${ }^{[6]}$. CA (carbazole), MCA (methylcarbazole) and DMCA (dimethylcarbazole) can be identified in oils by comparison of relative retention time and retention indices on $\mathrm{m} / \mathrm{z} 167,181,195$ mass chromatograms with those in published work. GC-MS analysis for aromatic fractions were performed using a HP-6890A gas chromatograph interfaced to a HP-5973 mass selective detector. Nitrogen-containing compounds (mainly dibenzofurans and alkyl dibenzofurans) and sulfur-containing compounds (mainly dibenzothiophenes and alkyl dibenzothiophenes) can be identified through different mass chromatograms.

\section{Result and discussion}

Through geochemical analysis of crude oils in study area using $\mathrm{GC} \times \mathrm{GC} / \mathrm{TOFMS}$ and GC-MS instrument, we determined the relative concentration of $\mathrm{N}-, \mathrm{S}-$, and $\mathrm{O}-$ containing compounds and some related typical parameters. Their spatial variation characteristics are analyzed, and on the basis of these analyses, the role of these parameters in indicating the direction of hydrocarbon migration is discussed. 


\subsection{Application of total concentration of NSO compounds}

The concentration of NSO compounds in crude oils in the study area is relative low, range from $0.04 \%$ to $0.25 \%$. The NSO compounds content analysis result of the samples shows that the content of samples that are close to the hydrocarbon-generating kitchen is lower, while the content of samples far from the hydrocarbon-generating kitchen is relatively high. From the characteristics of the planar variation of the relative content of NSO compounds, we can see that the content of the sample gradually increased from the deeper buried area to shallower buried area along two different directions, indicating two independent hydrocarbon migration pathways (Figure 3).

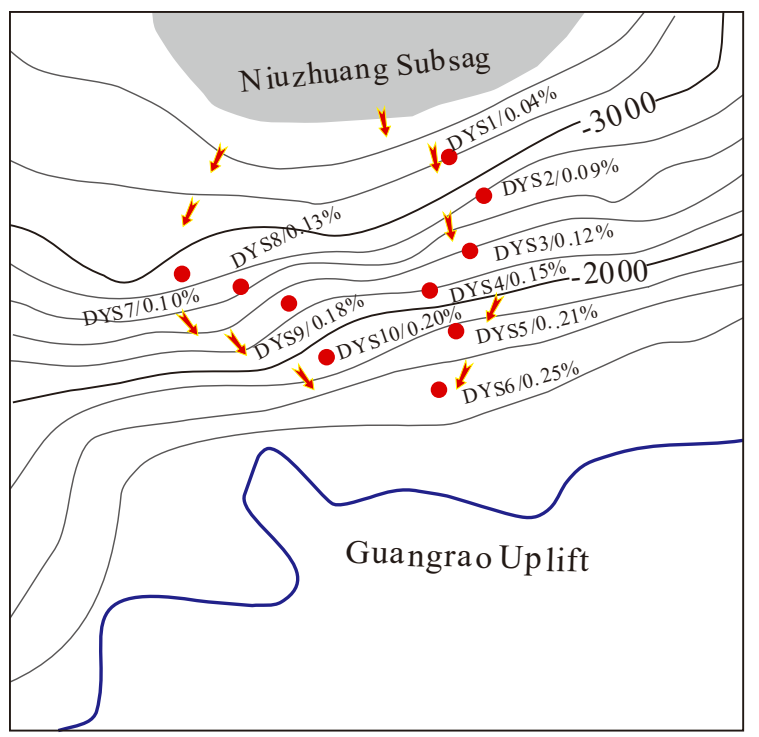

Figure 3. Variation of the total content of NSO compounds in the study area and the direction of hydrocarbon migration.

In order to further analyze the hydrocarbon migration indicator significance of the NSO compound content. The relative content of N-, S-, and O- containing compounds was analyzed comparatively. It seems that the Ocontaining compounds have the highest relative content, accounting for more than $50 \%$ of the total NSO compounds, while the relative content of $\mathrm{N}$-containing compounds is the lowest (Figure 4). The comparative results of the relative content of the $\mathrm{N}-$, S-, and Ocontaining compounds in different samples show that the correlation between the changes in their content and the migration distance is relatively poor, therefore their effectiveness in indicating the hydrocarbon migration direction is limited.

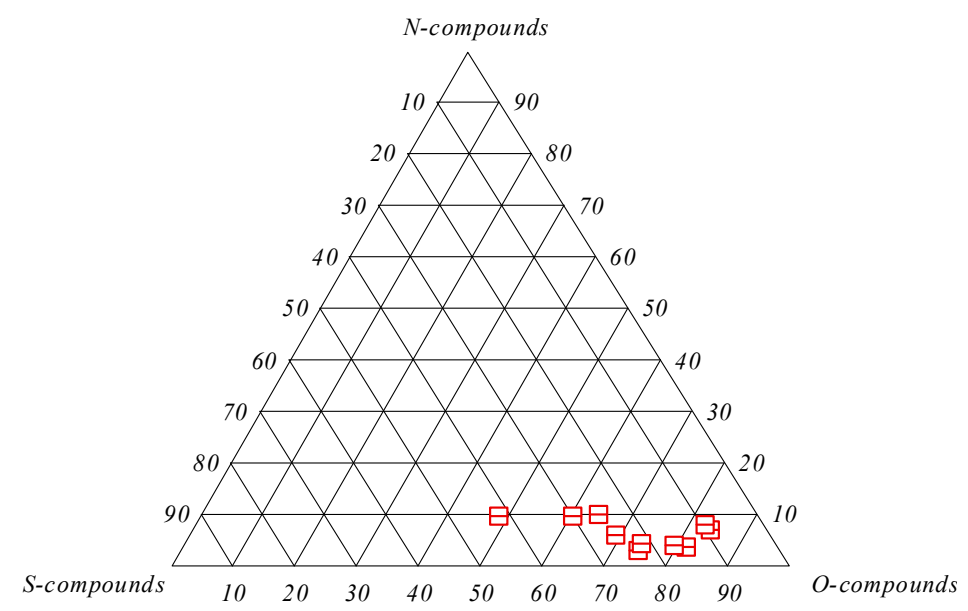

Figure 4. Ternary diagram of fluorene (F), dibenzofuran (DBF) and dibenzothiophene (DBT) of crude oils with different Sulfur (S) content in the study area.

\subsection{Application of $\mathrm{N}$-containing compounds}

Pyrrolic nitrogen compounds are known to interact with formation water and mineral surfaces, probably through hydrogen bonding between the pyrrolic N-H with hydroxy groups in the surrounding environment ${ }^{[7]}$. Due to different migration fractionation effects of pyrrolic compound isomers, petroleum migration was postulated to be characterized by regular changes in absolute concentrations and isomer ratios. The methylcarbazole (MC), dimethylcarbazole (DMC) and benzocarbazole (BC) are important pyrrolic nitrogen compounds which are widely used in indicating hydrocarbon migration direction. 
These compounds can be identified on mass chromatograms (Figure 5).

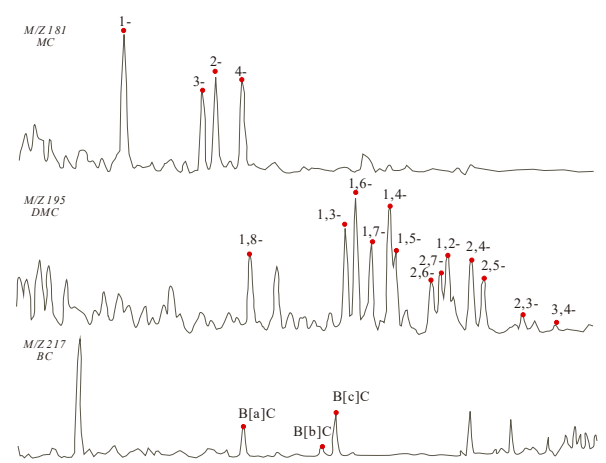

Figure 5. Mass chromatograms showing the MC, DMC and BC of oil samples from study area.

The pyrrolic nitrogen fractions obtained from analyzed samples comprise carbazole, benzocarbazole and dibenzocarbazole and their alkyl derivatives. The total concentration and ratios of selected groups of pyrrolic nitrogen compounds of analyzed samples are listed in table 1. The concentration of different compounds in these oils have large differences, whereas the distribution of these compounds are generally similar. The relative enrichments of $\mathrm{N}-\mathrm{H}$-shielded to $\mathrm{N}-\mathrm{H}$-exposed isomers with increasing migration distances have been confirmed. 1-/3-MC, 1-/4-MC, 1,8- /1,6-DMC and some other molecular indicators are widely used in tracing oil filling pathways and migration orientation. But not all parameters can be used to trace the direction of oil migration in the study area. From the previous analysis, it is clear that the migration direction of crude oil is DYS7 $\rightarrow$ DYS8 $\rightarrow$ DYS9 $\rightarrow$ DYS10 $\rightarrow$ DYS6. Our experimental results show that along hydrocarbon migration direction, 1-/3-MC and 1,8- /2,7-DMC increased progressively. However, the other listed parameters did not show very regular changes with the increase of the migration distance. This phenomenon shows that when using parameters related to nitrogen compounds to determine the direction of hydrocarbon migration, the results of other researchers should not be rigidly used, but should be selected based on the geological characteristics of the study area.

Table 1. The total concentration and ratios of selected groups of pyrrolic nitrogen compounds of analyzed samples in the study area.

\begin{tabular}{|c|c|c|c|c|c|c|c|c|c|c|c|c|}
\hline \multirow[b]{2}{*}{ Well } & \multicolumn{12}{|c|}{ Concentration } \\
\hline & 1-MC & 3-MC & 2-MC & 4-MC & \multicolumn{2}{|c|}{$\begin{array}{l}1,8- \\
\text { DMC }\end{array}$} & $\begin{array}{l}1,3- \\
\text { DMC }\end{array}$ & $\begin{array}{l}2,6- \\
\text { DMC }\end{array}$ & $\begin{array}{l}2,7 \\
\text { DMC }\end{array}$ & [a] & {$[\mathrm{b}]$} & [c] \\
\hline DYS7 & 0.565 & 0.171 & 0.190 & 0.635 & \multicolumn{2}{|c|}{0.434} & 0.361 & 0.130 & 0.085 & 0.232 & 0.421 & 0.329 \\
\hline DYS8 & 0.003 & 0.006 & 0.009 & 0.010 & \multicolumn{2}{|c|}{0.027} & 0.018 & 0.008 & 0.009 & 0.012 & 0.012 & 0.056 \\
\hline DYS9 & 2.972 & 1.742 & 2.118 & 2.727 & \multicolumn{2}{|c|}{1.405} & 1.879 & 0.816 & 1.245 & 1.231 & 0.227 & 1.013 \\
\hline DYS10 & 0.895 & 0.511 & 0.661 & 0.655 & \multicolumn{2}{|c|}{0.457} & 0.650 & 0.338 & 0.392 & 0.103 & 0.036 & 0.146 \\
\hline DYS6 & 0.547 & 0.291 & 0.441 & 0.315 & \multicolumn{2}{|c|}{0.319} & 0.415 & 0.140 & 0.176 & 0.043 & 0.090 & 0.107 \\
\hline \multirow[b]{2}{*}{ Well } & \multicolumn{12}{|c|}{ Ratio } \\
\hline & 1-/3-MC & \multicolumn{2}{|c|}{ 1-/4-MC } & \multicolumn{2}{|c|}{$\begin{array}{c}1,8-/ 1,6- \\
\mathrm{DMC}\end{array}$} & \multicolumn{2}{|c|}{$\begin{array}{r}1,8-/ 2, \\
7-\mathrm{DMC}\end{array}$} & \multicolumn{2}{|c|}{$\begin{array}{c}1,8-/ 1,3- \\
\text { DMC }\end{array}$} & \multicolumn{2}{|c|}{$\begin{array}{l}1,3-/ 1,6- \\
\text { DMC }\end{array}$} & {$[\mathrm{a}] /[\mathrm{c}]$} \\
\hline DYS7 & 0.51 & \multicolumn{2}{|c|}{0.30} & \multicolumn{2}{|l|}{3.93} & \multicolumn{2}{|c|}{1.13} & \multicolumn{2}{|l|}{1.48} & \multicolumn{2}{|l|}{2.65} & 0.17 \\
\hline DYS8 & 1.71 & \multicolumn{2}{|c|}{1.09} & \multicolumn{2}{|l|}{0.96} & \multicolumn{2}{|c|}{1.17} & \multicolumn{2}{|l|}{0.75} & \multicolumn{2}{|l|}{1.29} & 0.55 \\
\hline DYS9 & 1.75 & \multicolumn{2}{|c|}{1.37} & \multicolumn{2}{|l|}{0.58} & & .81 & 0.70 & & 0.82 & & 0.41 \\
\hline DYS10 & 1.88 & & .74 & 0.61 & & & .90 & 0.77 & & 0.80 & & 0.29 \\
\hline DYS6 & 3.31 & & 89 & 1.50 & & & .14 & 1.20 & & 1.25 & & 0.41 \\
\hline
\end{tabular}

\subsection{Application of S-containing and O- containing compounds}

Because sulfur-containing compounds and oxygencontaining compounds have a molecular structure similar to nitrogen-containing compounds, and a similar reaction mechanism with the transport layer during the migration process, some related geochemical parameters can also be used to identify the direction of hydrocarbon migration. In addition to changes in the migration process, other factors such as sedimentary facies, biodgredation, and thermal maturity also have effects on the concentration and distribution of the dibenzothiophene (S-containing) and dibenzofuran $(O$-containing) series. There is no obvious correlation between the migration direction tracer parameters and crude oil maturity, indicating that maturity has little effect on them (Figure 6). In addition, the crude oil samples selected in this study originated from the same set of source rocks, and none of them suffered significant biodegradation. Therefore, the changes in these parameters were mainly caused by hydrocarbon migration. 

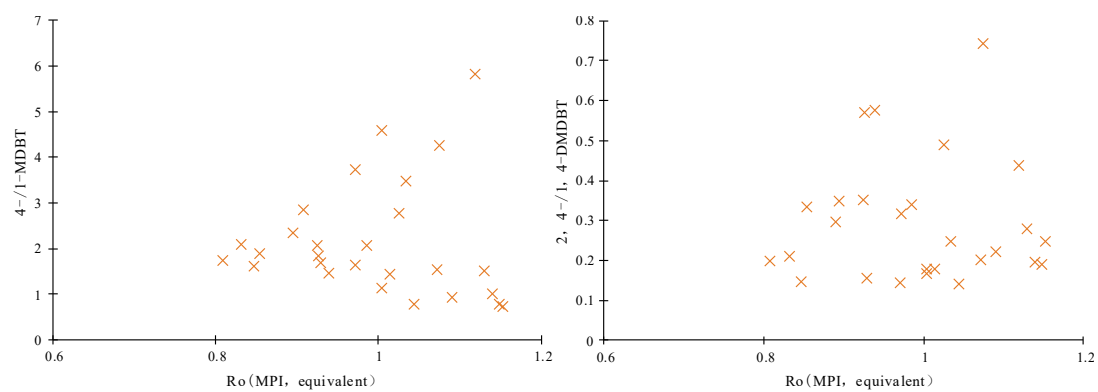

Figure 6. Cross-plots of selected migration direction tracing parameters and MPI equivalent Ro.

In this study, we selected 2,4-/1,4dimethyldibenzothiophene (2,4-/1,4-DMDBT, $S$ containing) ratio and 4-/1-methyldibenzofuran (4-/1MDBF, O-containing) ratio to study the hydrocarbon migration direction. Figure 6 shows the changes in geochemical parameters of different wells selected on a reservoir profile from the hydrocarbon generation center to the slope zone. With the increase of migration distance, 4-/1-MDBF ratio increase and 2,4-/1,4-DMDBT ratio decrease successively, demonstrating their good application potential in indicating the direction of hydrocarbon migration(Figure 7).

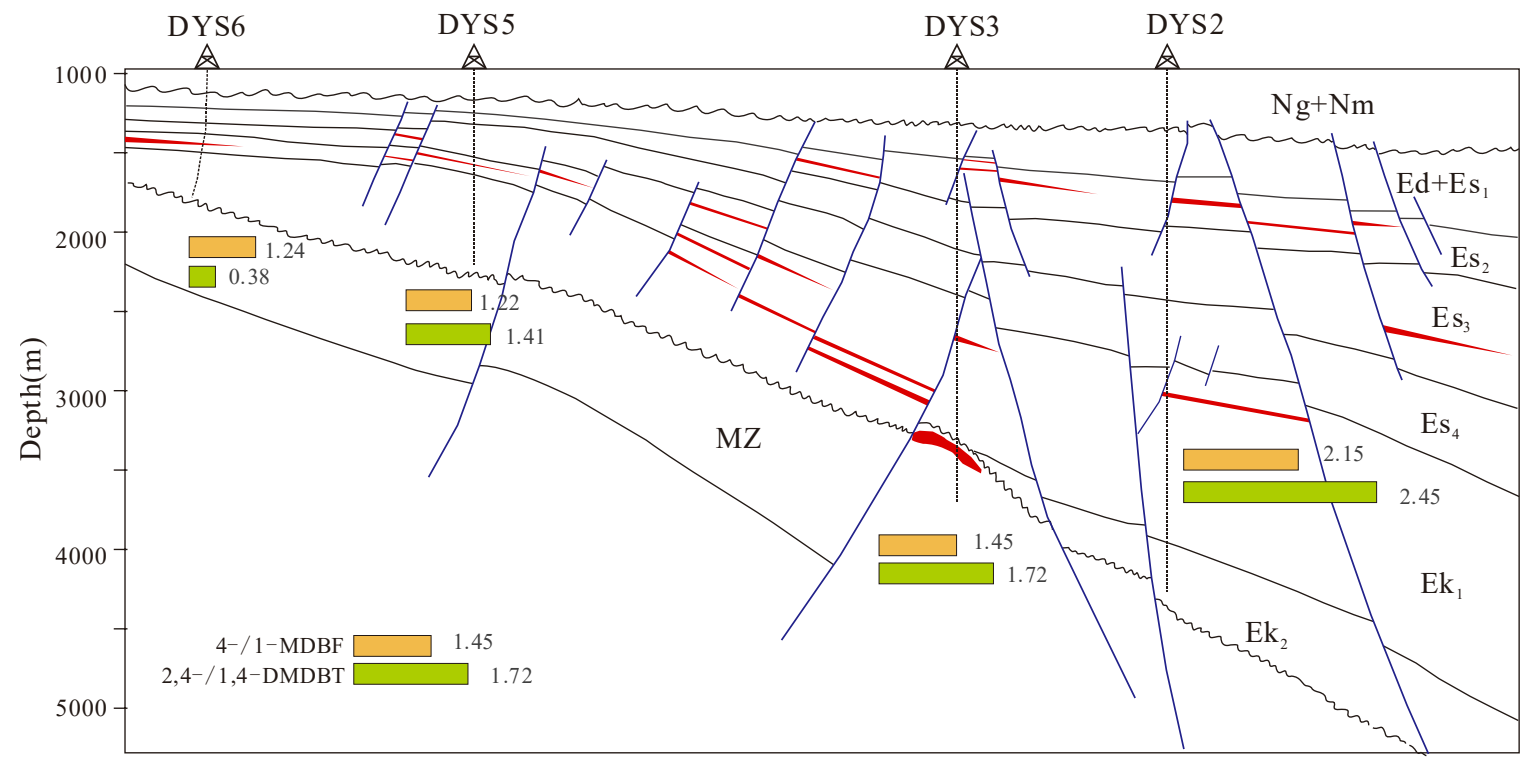

Figure 7. The 4-/1-MDBF and 2,4-/1,4-DMDBT ratios in a typical reservoir profile in the study area.

\section{Conclusion}

NSO compounds including polar N-, S-, and O- containing compounds are important tracers of hydrocarbon migration in petroliferous basin. Through systematic analysis of the characteristics of geochemistry and hydrocarbon migration on the southern gentle slope of the Dongying Sag, we confirmed that NSO compounds have good application potential in hydrocarbon migration direction tracing. Our research results show that the total amount of NSO compounds and NSO compounds related parameters can be used to indicate hydrocarbon migration. However, not all parameters can correctly indicate the direction of hydrocarbon migration. In order to maximize the effect of these tracer parameters and more accurately indicate the migration pathways of hydrocarbons, it is necessary to select parameters based on geological and geochemical characteristics.

\section{Acknowledgments}

This work was financially supported by Shengli Oil Field Branch Company fund "Quantitative technology and application of multiple series compounds and metal elements in crude oil"' (Fund number: YKS2001).

\section{References}

1. Hughey, C.A., Rodgers, R.P., Marshall, A.G., Qian, K., Robbins, W.K., 2002.Identification of acidic NSO compounds in crude oils of different geochemical origins by negative ion electrospray Fourier transform ion cyclotron resonance mass spectrometry. Organic Geochemistry 33, 743-759.

2. Larter, S.R., Bowler, B.F.J., Li, M., Chen, M., Brincat, D., Bennett, B., Noke, K., Donohoe, P., Simmons, D., Kohnen, M., Allan, J., Telnaes, N., Horstad, I., 1996. Molecular indicators of secondary oil migration distances. Nature 383, 593-597. 
3. Liu P, Li M, Jiang Q, et al. Effect of secondary oil migration distance on composition of acidic NSO compounds in crude oils determined by negative-ion electrospray Fourier transform ion cyclotron resonance mass spectrometry[J]. Organic Geochemistry, 2015, 78:23-31.

4. Li, M.J., Wang, T.-G., Shi, S.B., Liu, K.Y., Ellis, G., 2014a. Benzo[b]naphthothiophenes and alkyl dibenzothiophenes: molecular tracers for oil migration distances. Mar. Petrol. Geol. 57 (2), 403417.

5. Wand Shengzhu, Li Maorong, Qian Kebing, et al. Genesis types and accumulation characteristics of crude oil in Wangjiagang area, Dongying Sag[J]. Journal of oil and Gas Technology, 2006, 29(6):13-17.

6. Li M, Larter S R, Stoddart D, et al. Fractionation of pyrrolic nitrogen compounds in petroleum during migration: Derivation of migration-related geochemical parameters[J]. Geological Society London Special Publications, 1995, 86(1):103123.Larter S, Mills N, 1991. Phase-controlled molecular fractionation in migrating petroleum charges. In: England W A, Fleet A J, eds. Petroleum Migration. Geol Soc Spec Publ. 59: 137-147.

7. Peters K E, Walters C C, Moldowan J M. 2005. The Biomarker Guide:Biomarkers and Isotopes in Petroleum Exploration and Earth History. 2nd ed. Part II. Cambridge: Cambridge University Press. 4751155 